\title{
Oral Health Management of Cerebral Palsy in Paediatric Population
}

\section{Karthik Shunmugavelu*}

Senior Consultant, Department of Paediatric Dentistry, Kanchi Kamakoti CHILDS Trust Hospital, Chennai, Tamil Nadu, India

*Corresponding Author: Karthik Shunmugavelu, Senior Consultant, Department of Paediatric Dentistry, Kanchi Kamakoti CHILDS Trust Hospital, Chennai, Tamil Nadu, India

Received: July 19, 2019; Published: September 10, 2019

DOI: 10.31080/ASPE.2019.02.0145

\begin{abstract}
Cerebral palsy (CP) is a debilitating condition involving tonus, posture, movement due to lesion in central nervous system indirectly affecting the maturation stage. Any trauma during the conception and infancy can lead to CP. Multifactorial determinants includes neonatal anoxia, prematurity, low birth weight, prenatal meningitis, encephalitis, cerebral vasculitis viral infection and genetic malformations. Children with CP have increased incidence of dental caries and periodontal disease.
\end{abstract}

Keywords: Cerebral Palsy; Paediatric; TMJ

Oral health management of cerebral palsy in paediatric population

Cerebral palsy (CP) is a debilitating condition involving tonus, posture, movement due to lesion in central nervous system indirectly affecting the maturation stage [1]. Any trauma during the conception and infancy can lead to CP [2,3]. Multifactorial determinants includes neonatal anoxia, prematurity, low birth weight, prenatal meningitis, encephalitis, cerebral vasculitis viral infection and genetic malformations [4,5]. Children with CP have increased incidence of dental caries and periodontal disease [6,7].

The most common dental conditions observed in a CP child are listed as follows

- Dental Caries: Factors such as inability to toothbrush and floss, enamel hypoplasia, soft diet, mouth breathing habit and partial inability to communicate contribute to a high chance of food accumulation in the oral cavity, thereby leading to mutliple caries affected teeth.

- Temporomandibular joint (TMJ) disorders: Clinical findings such as tenderness upon palpation, pain

- during mouth open, closed and masticatory positions, deviated or restricted TMJ movements, crepitation, condylar luxation and hearing impairment.
- Periodontal disease: Gingival hyperplasia and poor oral hygiene are witnessed due to side effects of medicinal management.

- $\quad$ Salivary glands: Reduced salivary flow rate leads to decreased PH buffering action thereby resulting in increased dental caries.

- Malocclusion: Discrepancies in teeth alignment such as class II malocclusion, abnormal muscle, tongue movement, anterior open bite, trauma to anterior teeth, tooth mobility, longer anterior-posterior maxillary arch length, bruxism, crowded lower anterior teeth, dry lips and mouth breathing are usually seen.

- Bruxism: This condition is increased due to enamel hypoplasia. The lingual cusps of the upper permanent molars and buccal cusps of the lower permanent molars are usually involved leading to loss of vertical dimension.

- Enamel hypoplsia: Calculus, increased stain can accelerate the enamel hypoplasia.

- Dental erosion: Occurs due to gastro-oesophageal reflux.

- Miscellaneous: Incidence of supernumerary teeth, congenitally missing permanent teeth, difference in tongue size and cleft lip/palate seen. 
Dental management

- Periodontal management: Modification of regular toothbrushes, automatic toothbrushes, oral irrigation devices, antimicrobial mouthwashes, dental floss with holder and periodontal surgery either conventional or laser in case of gingival enlargements.

- Dental caries: Application of sealants and fluoride, composite restorations, glass ionomer restorations and stainless steel crowns.

- Dental alignment: Selective extraction of malposed tooth/teeth.

- $\quad$ Positioning devices: Stabilizing devices, restraints, protectives such as positioning bags, cushions, mouthwraps, seat belt and body wrap.

\section{General instructions}

- $\quad$ Short and clear instructions one at a time.

- $\quad$ Active in listening.

- Develop trust and reliability.

- Tell-Show-Do

- Apply gentle pressure.

- $\quad$ Prior information regarding any stimulus.

Intraoperative management during seizure

- Dental instruments to be removed from the oral cavity

- $\quad$ Space creation in the working atmosphere.

- $\quad$ Airway to be monitored to avoid aspiration.

- $\quad$ Call the emergency team [8]

Hence, it is a great challenge for a dental practitioner to manage a special child and deliver a successful outcome. A detailed knowledge, innovative and problem solving approach and treatment options play an important role in promotion of the oral health in these individuals. However, certain limitations in the treatment perspective should be clearly informed to the parents or guardian.

\section{Bibliography}

1. Dougherty NJ. "A review of cerebral palsy for the oral professional". Dental Clinics of North America. 53 (2009): 329-38.

2. Castilho DPL, et al. "Estimulação motora precoce para portadores de paralisia cerebral: orientações aos pais e cuidadores". Reabilitar 7.29 (2005): 52-56.

3. Schwartzman JS. "Paralisia cerebral". Arqu Brasil Paral Cerebr 1.1 (2004): 4-7.
4. Costa MHP., et al. "Perfil clínico-epidemiológico de pacientes com Paralisia Cerebral assistidos em um centro de odontologia do Distrito Federal". Com Ciências Saúde 18.2 (2007): 129-139.

5. Guerreiro PO and Garcias GL. "Diagnóstico das condições de saúde bucal em portadores de paralisia cerebral do município de Pelotas, Rio Grande do Sul, Brasil". Ciênc. Saúde Coletiva 14.5 (2009): 1939-1946.

6. "Untreated dental caries in children with cerebral palsy in the Brazilian context". International Journal of Paediatric Dentistry 18.2 (2008): 131-138.

7. Pope JE and Curzon ME. "The dental status of cerebral palsied children". Pediatric Dental 13.3 (1991): 156-62.

8. Rodrigues dos Santos., et al. "Oral conditions in children with cerebral palsy". Journal of dentistry for children 70.1 (2003): 40-46.

\section{Volume 2 Issue 10 October 2019 \\ (C) All rights are reserved by Karthik Shunmugavelu.}

\section{.}

